\title{
Research on Integration and Interaction of Southern Fujian Culture Creative Industry and Quanzhou Tourism
}

\author{
Caizhen Hong \\ Quanzhou Normal University \\ Quanzhou, Fujian Province, China, 362000. \\ email: hongcaizhen2@126.com
}

\begin{abstract}
Quanzhou has achieved great success in tourism industry in recent years, however, problems exist in that tourists staying time is short, the income structure is unreasonable, and the tourism industry chain is imperfect. The problems indicate that Quanzhou has lacked creative tourism product design based on Southern Fujian culture. Creative industry based on Southern Fujian culture can bring new revenue increase for Quanzhou tourism development. The integration and interaction modes of creative industry and Southern Fujian culture include "nidificate for attracting phoenix", "add brilliance to one's splendor", and "combination of virtual and reality".
\end{abstract}

Keywords-Tourism Industry; Creative Southern Fujian Culture; Integration and Interaction Mode

\section{INTRODUCTION}

\section{A. Existing Tourism Industry Problems}

Quanzhou is located in the southeast coast of Fujian province, a strait away from Taiwan. It is one of the first 24 famous historic cities of culture designated by the State Council. Quanzhou is a coastal city with mountains and beautiful scenes. Since the Reform and Opening, Quanzhou tourism industry has developed very fast, which has great contribution to the industry structure transformation and upgrade. In 2011, the total tourism revenue of Quanzhou was 23.215 billion Yuan ( $3^{\text {rd }}$ in Fujian). It received 846.4 thousand foreign visitors $\left(2^{\text {nd }}\right.$ in Fujian) and foreign exchange earning was 797 million dollars ( $3^{\text {rd }}$ in Fujian). The amount of visitors reached 26.199 million $\left(3^{\text {rd }}\right.$ in Fujian), and revenue was 18.036 billion Yuan $\left(4^{\text {th }}\right.$ in Fujian).While emphasizing the accomplishment of Quanzhou tourism, problems exist in that total tourism revenue accounts for a small proportion of Gross Domestic Product (GDP) and there is lone source of visitors. From Southern Fujian creative culture design perspective, two more problems exist as listed below:

1) Visitors are mainly on One Day Tour and Stay for Short Time:Based on 2005 survey, the amount of visitors on one day, two days and three days tour accounts for $48.39 \%$, $25.56 \%$ and $26.05 \%$, respectively. Until now, the majority of tours are still one day tour. During the May $1^{\text {st }}$ labor's day holiday in 2012, Fujian received 3.9892 million international and domestic tourists, in which 3.0877 million was on one day tour $(77.4 \%)$. The percentage is above $80 \%$ in Fuzhou, Zhangzhou, Quanzhou, Putian, and Sanming, higher than average of Fujian.

2) Tourism revenue structure is unreasonable, and industry chain is imperfect:The average expense in Quanzhou from domestic tourists in 2011 was about 1156.2 Yuan, higher than average of Fujian (1001.6 Yuan). This number ranked $3^{\text {rd }}$ in Fujian, and was lower than Xiamen (1371.2 Yuan) and Nanping (1192.7 Yuan). The international tourist average expense in Quanzhou was $\$ 941.6$ ( $^{\text {nd }}$ in Fujian), higher than average of Fujian (\$850.2), and was only lower than Fuzhou (\$1349.6). The ranking is good, but the expense was mainly on entrance tickets. Among six factors of tourism, proportion of expense on eating, lodging, traveling and sightseeing are higher than entertaining and shopping. Shopping, as one of the six factors, should account for major proportion of expense. In many countries and areas the tourism income from tourists' shopping accounts for 30-40\%. In Hong Kong and Singapore, the proportion is as high as $50 \%$. But in Quanzhou, it is 15\%. [1] This indicates that Quanzhou tourism industry chain is imperfect and the income structure is unreasonable.

\section{B. Analysis and Discussions}

Tourists stay for a short time in Quanzhou, mostly on one day tour; the tourism industry chain is imperfect, entertaining and shopping expense is low. These indicate there are serious problems on the tourism product design. The current tourism product in Quanzhou is mainly static sightseeing, low level and single structure. Participating and experiencing tourism product that full of Southern Fujian creative culture is deficient. The extensive development mode without innovation and cultural connotation indicates that Quanzhou tourism industry and Southern Fujian culture creative industry has little integration and interaction. Culture creative industry focuses on product uniqueness, creativity and artistry and has enormous brand expansion potential. Quanzhou has huge potential for culture creativity since it is the core area of Southern Fujian culture and has the United Nations' first "exhibition center of world multiculturalism". However, its resources are not fully explored. Besides essential capital and talents, culture creativity is the key to improve the product competition since resource itself can't transform into culture product 
advantage. Only when the resources are combined with creativity can they transform from historical value and art value into commercial value.

It is a trend for the culture, creativity and tourism industry to integrate. The culture industry is to provide culture, entertainment product and service for public. The tourism involves various areas of six factors including traveling, sightseeing, lodging, eating, shopping and entertaining and various departments relevant to the tourist expense. Creative industry is a high end value chain industry emphasizing on thought, idea, knowledge, information and culture. [2] It has creativity, penetrability, high increasing value ability, strong radioactivity and high technology features, and integrates tourism resources, innovates tourism products, enriches tourism industry chain, and restructures industry system. As compared to traditional tourism, creative tourism is emphasized on creativity, which is reflected on the "planning" of the culture tourism resources exploration and development, and expedites industry structure optimization, transformation and upgrade, strengthens product attraction, expands the tourism market, and promotes the tourism transformation from extensive model to intensive model. [3]

Quanzhou has high level culture tourism resource because its religious building and relic account for very high percentage. The religious tourism, for example, is the most important component in Quanzhou tourism and its source of visitors is mainly Chinese from Hong Kong, Macao, and Taiwan who do pilgrimage, visit relatives, do business study and sightseeing. Religious tourism is the most ancient form of tourism, and its market is considered the largest, with stabilized need and good tourist sources. As a world religious museum, Quanzhou has a long history of religion, multiculture, many religious relic and sites and high value resources. Quanzhou has many intact ancient palace and temple buildings and large amount of temples, grave, monument, stone carvings, Confucian classics and religious scriptures, which have history, culture and art values. However, its religion related product design has lacked of Southern Fujian culture creativity and participation. Kaiyuan Temple, Laojun Rock, Qingjing Temple, Lingshan Tomb, and Straw Buddhist Convent were reproduced without Southern Fujian culture creativity; the tourism product is in its original status; and the tourists can only see but can't participate. All of these can't meet the tourists' need of new, curiosity, and participation. [4] The lack of creative marketing, the single narrow religious tourist source, and the lack of attraction for tourists from other area and other types resulted in the narrow international market, single tourist source, slow growth of the whole tourism market and lack of attraction for domestic non-religious tourists

"Entertaining" is one of the six factors of tourism. Currently, it is very common to develop large culture show directly as a tourism product. For example, the classic show in Broadway in New York is a very important tourism product. ERA- Time and Space tour in Shanghai, "JinSha" Stage show in Chengdu, "Yunnan Image" in Kunming has been performed every year, and become an attractive experiencing tourism product. Quanzhou is called the hometown of traditional opera and has rich opera show, such as Liyuan opera, suspended puppet opera, hand puppet opera, Dacheng opera, and Gaojia opera. Chest patting dance full of ancient MinYue style and southern music, an elegant Tang dynasty music, are not only famous in Southern Fujian area, but also in Hong Kong, Macao, Taiwan and Southeast Asia, and become important tourism resources of Quanzhou. However, creative Southern Fujian culture entertainment show is deficient. Listening to southern music became one of the relaxing life style in Quanzhou. The southern music show and the tea house are only arranged for some high class figures other than ordinary people. Large drama "Bright City" in 2006 did not achieve similar culture and economic benefits as "Impression of Liu Sanjie". [5] In April 2011,stage opera "Marry in Ancient House" integrating southern music, hand puppet opera and Liyua opera was introduced to the tourists. The goal was to break the dilemma of "see the temples in the day time, sleeping at night". Whether or not this is a name card for Quanzhou has yet to be verified by time and market.

According to the agenda of many travel agencies in Fujian, tourists have only one day to visit Kaiyuan Temple, Laojun Rock, and Qingjing Temple in Quanzhou, and then turn to other places in Fujian. For most individual visitors, they can only feel the economic growth and the rapid change of Quanzhou city, and tea stores and tea houses everywhere, but not traditional culture, Southern Fujian culture, sea silk culture or even tea culture. The tourism product did not extend from day to night.[6] If Quanzhou can develop creative entertainment show with Southern Fujian culture in tourism market, it can slow down the visitors and let them stay longer, and avoid being the tourism transfer station of Fuzhou and Xiamen.

Entertaining and shopping are two indispensable factors in tourism. Shopping in Quanzhou tourism only accounts for $15 \%$, which does not comport with the developed private economy, and indicates the design of Quanzhou tourism product has severe problems. Economy in Qunzhou is in good position in Fujian and China. Quanzhou shoe, hat and clothing industry has its certain position in China or even in the world. Porcelain, stone carving, tea, paint basket tourism products are famous around the world. Quanzhou's entertainment industry has developed recently, but the entertaining and shopping are still a weak link in Quanzhou tourism.[4]

\section{THEORETICAL BASIS OF INTEGRATION AND INTERACTION OF SOUTHERN FUJIAN CREATIVE INDUSTRY AND QUANZHOU TOURISM}

\section{A. Overview of Culture Creative Industry}

Since the $21^{\text {st }}$ century, technology innovation and culture creativity have become two engines of modern economic growth. In the background of knowledge economy and post industry era, culture creative industry is worthy of the "morning industry", its scale and extent of development has become an indicator of competitive index 
of a country or area. Culture creative industry is not only a high technology, low resource consumption, but also low pollution, and high development potential industry that is considered by many as an important direction of Chinese economic structure transform. Tourism industry is interconnected to culture creative industry, which provides new increasing point for tourism, and has sustainable renewal, high brand influence, strong integration and high extra values. The highest status and direction of tourism is to integrate creative industry and tourism industry.

\section{B. Theory on Industry Integration and Interaction}

Theory on industry interaction and integration originated from idea of industry integration, and was from Rosenberg's research on American machine tool industry evolvement. [7] Integration of creative industry and related industry has become a trend in the world, and its internal driving force is the interconnection and pursuit of maximized benefit. Tourism and creative industry has natural and inevitable connections. Tourism culture creative industry has been considered future tourism industry development direction. Through leveling, serializing, and quality improving of tourism product, and personalized communication service, integrated "creative tourism industry" can increase the number of product types, optimize product structure and promote product brand, can accomplish increasing industry values, competiveness, innovation of tourism product to assure optimization of tourism industry structure and development mode transformation and upgrade. [8]

\section{INTERACTION AND INTEGRATION MODELS OF SOUTHERN FUJIAN CREATIVE INDUSTRY AND QUANZHOU TOURISM}

A. "Nidificate for Attracting Phoenix" Model: Southern Fujian Culture Creative Tourism Garden Model

The model is to build "one station experience" creative industry garden including six factors of tourism, reduce customs' searching cost by share of resources (especially culture talents, creative knowledge), and form complete Southern Fujian culture tourism industry chain with production-supply-marketing integration. This chain includes subject garden, film and television animation base, art garden, and fashion street. In the $11^{\text {th }}$ five year plan, Quanzhou built seven province level and eighteen city level culture industry show bases such as "Liujingkong" music culture creative garden, Jinxiuzhuang Southern Fujian culture creative garden, Yuanhetang creative garden, Fengze district relaxation culture creative base, Ling Show Tiandi creative garden, Qingyuanshan Yiyantang culture creative garden, Xinyu software modern service town, and Donghai film and television town, etc.. Further improvement should be made on hardware in the garden such as parking lot, eating and lodging place, water and electricity, and network utility. In addition, related software should be created as well, such as protecting intellectual property right, providing finance support, and tolerating different life styles of creators. For intellectual property right, the key of culture tourism creative industry is creativity and innovation, which is individual intellectual achievement, invisible and easy to imitate. Only the law can protect the creators' motivation. For finance support, investing creative design has high cost in the early stage that the small companies can't afford. The government's finance support can help the start-ups to overcome the early difficult situation. For tolerance, American scholar Richard Florida states that there are three main factors to form creative city: Talent, Technology and Tolerance, namely "3T" principle. [9] Tolerance means co-exist of multiple cultures, multiple factors, multiple formats and emphasis on residential mentality, community life style and city development environment of opening, inclusiveness, absorption, and communication such as SOHO, Bohemia wind. It will help the gathering of the creators, motivation of creative ideas and emergence of creative factors. [10]

B. Add Brilliance to one's Splendor Model: Traditional Project Plus Creative Industry Model

The model is to integrate creative industry into sub industry of tourism as a creativity driving force, to form new increasing point, extend tourism function, increase consumption experience and promote tourism attraction. The example of this model includes experiencing items, old area reconstruction, festival activity, large real scene show, and derived tourism product design.

Tourists experiencing product development should be carried out. Except for listening to the explanation of porcelain product design, tourists can be guided by professional artist to do it themselves based on their preference: from design, construct, drawing, painting and burning to making their souvenir. The same creative idea can be used on Huian's stone carving, Yongchun paper drawing, Anxi blue clothing with embroidered flowers, Licheng puppet head, and Yongchun's painted basket. Quanzhou music opera dance such as southern music, Liyuan opera, puppet opera, Dacheng opera, Gaojia opera and chest patting dance can also be designed as culture experiencing tourism. Let the tourists involve in simple show guided by the actors, playing special instruments such as Chinese lute, two string fiddle, flute, South drum, clappers etc., develop opera related tourism souvenir, such as audio-video products, books, picture album, post card, calendar, bookmark, props, and headwear. [11] Festival activity is the easiest to be designed as experiencing product, such as "jump cross fire pan", car drum, and tea competition folk custom activity, Lantern Festival, Fujian Taiwan culture festival (dragon boat water splashing festival), Magpie Festival, pudu, mid-autumn moon-cake gambling, cross strait Southern Fujian culture festival, Zhengchenggong culture festival, Anxi Tieguanyin tea garden tourism festival, Huian women custom culture festival, Fengshan culture tourism festival, Yongcheng peach blossom festival, and Yakou beach tourism culture festival. Quanzhou tea art and cuisine can be included into the tourism activity. Not just looking and tasting, tourists can learn the tea art guided by the masters, and cook Quanzhou cuisine, experience Quanzhou tea culture and cuisine culture. In the rural area tour, tourists can develop 
experiencing items like reaping, picking tea leaves, making tea, making fishing nets and fishing, etc. rural area production and life items.[12]

\section{Combination of Virtual and Reality: Tourism} Digital Creativity

This model involves cooperating with major web portals, major tourism reservation web, to develop virtual digital stage (network, cell phone) and real stage (traditional media) resources, using blog, youtube, bbs, weibo, traveling forums, email and QQ group, integrating marketing, e-business, network experiencing tour, to reach goals of increasing product channel, and extending tourist sources market. Quanzhou can cooperate with software companies to develop area tourism digital stage by gathering tourism government service, information service, e-business, network experiencing tour together as an integrated comprehensive platform. Also, Quanzhou can use invisible connection to integrate scattered tourism resources, use Quanzhou mountain and sea scene, Southern Fujian myth and legend, Zhengchenggong recovering Taiwan, Tang, song, yuan Erythrina port and Europe and Asia Africa sea trading, each Southern Fujian culture art symbol as a resource to make interacting animation, game, film and television, to conduct marketing using implanting, and lead new tourism consumption.[13]

Currently, Quanzhou has such websites: traveling administration official website http://www.qztour.com/, Quanzhou digital culture website http://www.qzcul.com/, and Quanzhou culture and ecosystem protection website http://www.mnwhstq.com/was40/tsg-index.jsp. It has rich resources but after browsing the websites, the author found that they focus on literal words and pictures but have very few audios and videos, its streaming is slow and can't be downloaded. There are very few network games, no virtual tour development, and no animation and film and television resources related to Southern Fujian culture. Tourism forum has few comments and posts and lacks of interacting. The website is mainly owned by the government.

The popularity of Quanzhou tourism will be increased if government or non-government organization can develop communicating website similar to "backpackers" in Taiwan, and let the tourist from all around the world to communicate the tourism information, solve problems during tour, and share their experience. "Backpackers" is a special group of tourists who are normally higher educated, interested in area culture, and can touch the original culture by involving in the folk customs. They have special feeling and literal ability to describe various traveling notes, strategy and comments, take pictures and videos from special perspective, and communicate with other tourists around the world. Thus they can increase the tourism destination popularity. For example, the terrace of Hani minority in Yuanyang, Yunnan, was famous because of pictures taken from the backpackers from inside and outside the country. Therefore, even though the backpacker tourists do not lodge and eat in the local hotel, the local government with vision can still catch their needs, settle the backpacker temps, assist hosting drawing exhibition, picture exhibition and creative culture festival, and let them comment in the virtual space as a free advertisement.

\section{CONCLUSIONS}

As summarized above, Quanzhou has achieved great success in tourism industry in recent years, however, problems exist in that tourists staying time is short, the income structure is unreasonable, and the tourism industry chain is imperfect. The problems indicate that Quanzhou has lacked creative tourism product design based on Southern Fujian culture. Creative industry based on Southern Fujian culture can bring new revenue increase for Quanzhou tourism development. The integration and interaction modes of creative industry and Southern Fujian culture include "nidificate for attracting phoenix", "add brilliance to one's splendor", and "combination of virtual and reality"

\section{ACKNOWLEDGEMENT}

This research was financially supported by Fujian Higher Education Service on the project of Western Strait Construction (B053), and 2012 Fujian Education Department class "A" philosophy and sociology research plan curriculum (the name of project is: research on the interaction of Quanzhou tourism industry and Southern Fujian culture creative industry, project number: JA12235S); 2012 Quanzhou normal university curriculum reform and project name: problem of college tourism administration major student loss and education resolution measures (project number: $\mathrm{H} 22$ ).

\section{REFERENCES}

[1] Ye Chengfeng, Tourism product development strategy research on historical cultural city in the West Strait: Quanzhou tourism product market[J], Technology and Industry, 2011, (12):23-26.

[2] Wang zhaofeng, Yang qin. National culture tourism creative industry development research based on intellectual property theory. Guizhou nationality research, 2010, (5): 99-104.

[3] Chen Shulan, Liu Liping, Fu Jingbao. Henan province tourism industry structure optimization upgrade research - from culture creativity perspective. Economic Geography, 2011, (8): 1392-1396.

[4] Li Wenshi, SWOT-PEST analysis on Quanzhou culture and tourism development research [J]. Neijiang Normal University newspaper, 2011, (10): 67-72.

[5] Li Wenshi, Quanzhou ocean culture tourism resources characteristic and its development research [J], Guizhou Normal University newspaper, 2011, (9):29-32.

[6] Li Bin, West of strait economic areas culture tourism industry development. Master's Thesis of Fujian Normal University, 2008: 24-25.

[7] Rosenberg N. Technological change in the machine tool industry, 1840-1910[J]. The Journal of Economic History, 1963, 1(23) : 414-443.

[8] Xia Xiaoli, Wang Zhaofeng, Tan Bisi, Culture creative tourism industry development research - from industry value chain perspective[J]. China Collective Economy, 2009, (33): 136-137.

[9] Richard Florida, Rising of creative class[M]. Beijing: Zhongxin Press, 2010: 286.

[10] Feng Xuegang, Yu qiuyang, Integration and development of creative industry and creative city[J]. Sociology, 2010, (11): 13-18. 
[11] Zhao Yimin, Zheng Xiangmin, Quanzhou tourism products' experiencing design[J]. Heihe College newspaper, 2010, (3): 44-48.

[12] Zheng Weimin, Research of Quanzhou tourism product structure optimization. Quanzhou Normal University Journal (Natural Science) 2000, (6): 32-36.

[13] Li Xuerui, Huang Xijia, Tian Fengjuan, Liu Ling, Poyang Lake ecological economic area tourism industry upgrade research: creative industry as driving force[J]. Special Administrative Region Economy, 2011, (6): 152-153. 